\title{
Brief Communication: Mapping river ice using drones and structure from motion
}

\author{
Knut Alfredsen $^{1}$, Christian Haas ${ }^{2}$, Jeffrey A. Tuhtan ${ }^{3}$, and Peggy Zinke ${ }^{1}$ \\ ${ }^{1}$ Department of Civil and Environmental Engineering, Norwegian University of Science and Technology, \\ 7491 Trondheim, Norway \\ ${ }^{2}$ I AM HYDRO GmbH, Märtishofweg 2, 78112 St. Georgen, Germany \\ ${ }^{3}$ Centre for Biorobotics, Tallinn University of Technology, Tallinn, Estonia
}

Correspondence: Knut Alfredsen (knut.alfredsen@ntnu.no)

Received: 18 September 2017 - Discussion started: 9 October 2017

Revised: 29 December 2017 - Accepted: 17 January 2018 - Published: 21 February 2018

\begin{abstract}
In cold climate regions, the formation and breakup of river ice is important for river morphology, winter water supply, and riparian and instream ecology as well as for hydraulic engineering. Data on river ice is therefore significant, both to understand river ice processes directly and to assess ice effects on other systems. Ice measurement is complicated due to difficult site access, the inherent complexity of ice formations, and the potential danger involved in carrying out on-ice measurements. Remote sensing methods are therefore highly useful, and data from satellite-based sensors and, increasingly, aerial and terrestrial imagery are currently applied. Access to low cost drone systems with quality cameras and structure from motion software opens up a new possibility for mapping complex ice formations. Through this method, a georeferenced surface model can be built and data on ice thickness, spatial distribution, and volume can be extracted without accessing the ice, and with considerably fewer measurement efforts compared to traditional surveying methods. A methodology applied to ice mapping is outlined here, and examples are shown of how to successfully derive quantitative data on ice processes.
\end{abstract}

\section{Introduction}

River ice is a critical part of the cryosphere (Brooks et al., 2013), and ice formation has implications for river geomorphology, instream and riparian ecology, winter water supplies and for hydraulic engineering in cold climates. Physically monitoring and mapping ice is methodologically chal- lenging, as accessing river ice is difficult and potentially dangerous. Therefore, remote sensing methods are applied to assess ice in rivers and a number of examples of this exist in literature. Chu and Lindenschmidt (2016) integrated optical (MODIS) and radar (RADARSAT-2) satellite data to assess freeze-up, break-up, and ice types in the Slave river, Canada. They also used aerial- and terrestrial imagery to validate the satellite data, and found good agreement on break-up and freeze-up dates. Mermoz et al. (2014) demonstrated how ice thickness could be derived from RADARSAT-2 data for three rivers in Canada. Beltaos and Kääb (2014) used successive satellite images to assess the flow velocity and discharge during ice break-up, illustrating the ability of using remote sensing for studying ice process dynamics. Ansari et al. (2017) developed algorithms to automatically derive ice phenology data from bankside photography, and produced time series of these ice data for the lower Nelson River, Canada. Most satellite-based approaches described in the literature are applied to large rivers and may not apply to smaller rivers and streams due to the coarse resolution of the satellite imagery. Remote sensing methods are therefore needed to monitor ice formation in smaller rivers. Further work is also needed to move from a qualitative evaluation of ice (focussing on ice types and presence or non-presence of ice) towards a quantification of ice volumes and the spatial distribution.

These gaps may be filled by the use of inexpensive aerial drones with camera systems of sufficient quality that the resultant aerial imagery can be processed using the Structure from Motion (SfM) method (Westoby et al., 2012) into a three-dimensional surface representation of the area covered 
by aerial photography. Ground control points can be used to georeference the point cloud and aerial images generated by the drone, in order to develop digital elevation models of high accuracy and resolution. Additionally, surface texture may be derived and overlaid on the surface models, and derived georeferenced orthophoto mosaics to provide an accurate aerial image of the study object. SfM has shown great potential within geosciences where detailed digital models are often needed (Westoby et al., 2012; Smith et al., 2016), and the method has been applied, for example to studies on river habitat and hydromorphology (Woodget et al., 2017), erosion and sedimentation studies (Smith and Vericat, 2015), and for grain size classification (Vasquez-Tarrio et al., 2017; Arif et al., 2016). Within the cryospheric sciences this method has been used in the study of glaciers (Ryan et al., 2015) and in the study of snow accumulation (Nolan et al., 2015).

Combining a drone with SfM may be an efficient tool for mapping ice in rivers of various sizes, with the added advantage of also being able to cover small streams. This approach may enable detection of ice jams formed during ice runs, and anchor ice dams formed during freeze-up. These dynamic ice forms are difficult and time consuming (sometimes impossible) to map using traditional methods, but are important to many ice assessments. Ice break-up and associated jams can cause erosion and flooding, and thus severe damage to infrastructure and the riverine flora and fauna (Beltaos, 1995; Prowse and Culp, 2003). Anchor ice dams control the freezeup process in small rivers and streams, and are thus important for understanding winter conditions in such streams (Stickler et al., 2010; Turcotte and Morse, 2011). A possible drawback with the use of small drones as employed here their is limited flight distance (typically 1000-1300 m) and battery life in cold conditions.

In this brief communication, we outline the process of mapping river ice with a common, consumer-grade drone combined with commercial SfM software. Furthermore, we use the method to map the remnant of a stranded ice jam in one river section another river section with anchor ice dams. Cross sections and the volume of the ice run are computed from the mapped data, and the location and size of the anchor ice dams are estimated. Since these quantitative data are not commonly produced due to the difficulties associated with traditional field measurements, the application of the method presented has the potential to increase the amount and quality of data available. This may further improve our understanding of ice processes that form the foundation for modelling and practical assessments of ice impacts to constructed and natural environments.

\section{Materials and methods}

\subsection{Study site}

Our two study sites are located at the river Gaula $\left(63.06^{\circ} \mathrm{N}\right.$, $\left.10.29^{\circ} \mathrm{E}\right)$ and the tributary Sokna $\left(62.98^{\circ} \mathrm{N}, 10.22^{\circ} \mathrm{E}\right)$ south of Trondheim, Norway. We mapped a stranded part of an ice run that took place in December 2016 at the Gaula site close to Haga bridge and at the Sokna site we mapped a section of the river with several broken anchor ice dams. The drone flight was carried out in February 2017 under sparsely clouded conditions with low wind velocities. The length of the reaches mapped are 350 and $200 \mathrm{~m}$ for Gaula and Sokna, respectively. During the measurements, the discharge in Gaula (at the Gaulfoss gauge) was approximately $20 \mathrm{~m}^{3} \mathrm{~s}^{-1}$ and in Sokna (at the Hugdal bridge gauge) approximately $3.5 \mathrm{~m}^{3} \mathrm{~s}^{-1}$. These rates correspond to $28 \%$ of the mean annual flow. The Gaula site is about $75 \mathrm{~m}$ wide, and the water flows mainly over a bed of coarse gravel and small cobbles. At the location where the ice jam formed, the river narrows and the flow changes from a section with fast riffles to a deeper pool area. The Sokna site is steep $(1 / 100)$, the bed consist of large cobbles and boulders, and the river is characterised by short pools interspersed with drops and fast riffles/rapids. The width of the reach is around $18 \mathrm{~m}$.

\subsection{Data collection and processing}

At the two sites we acquired aerial images using a DJI Phantom3 Professional drone (www.dji.com), and surveyed ground control points (GCPs). The drone has a GPS/GLONASS assisted hover function and the 12 megapixel on-board camera has a $f / 2.894^{\circ}$ field of view and is mounted with a three-axis gimbal. The flight level was set to $30 \mathrm{~m}$ above the ground, but the level varied during the flight due to wind, pressure changes and the automated hover function. Most pictures were taken in plan view, but some oblique pictures were taken to better capture vertical features of the ice formations. A minimal image overlap of $20 \%$ was used to ensure good picture alignment in the SfM analysis. For both sites, the drone was manually controlled from the ground using the DJI remote controller and an Apple iPad with the DJI Go application. Though capable of autonomous operation according to a pre-planned flight plan generated with the DJI GS Pro application, the drone was controlled manually due to the size of the study area and regulations on unmanned aerial vehicle (UAV) operation. Each picture taken was stored on board the drone with its associated Exif image information and GPS position. A total of 215 and 517 pictures were taken of the Gaula and Sokna sites, respectively. Of these, 82 pictures were used in the SfM analysis for Gaula (38\%) and 68 pictures in Sokna $(13 \%)$. The time spent in Gaula was about 15 min for rigging and then $17 \mathrm{~min}$ for acquiring the imagery. At the Sokna site, the drone was already rigged and the flight lasted $10 \mathrm{~min}$. 


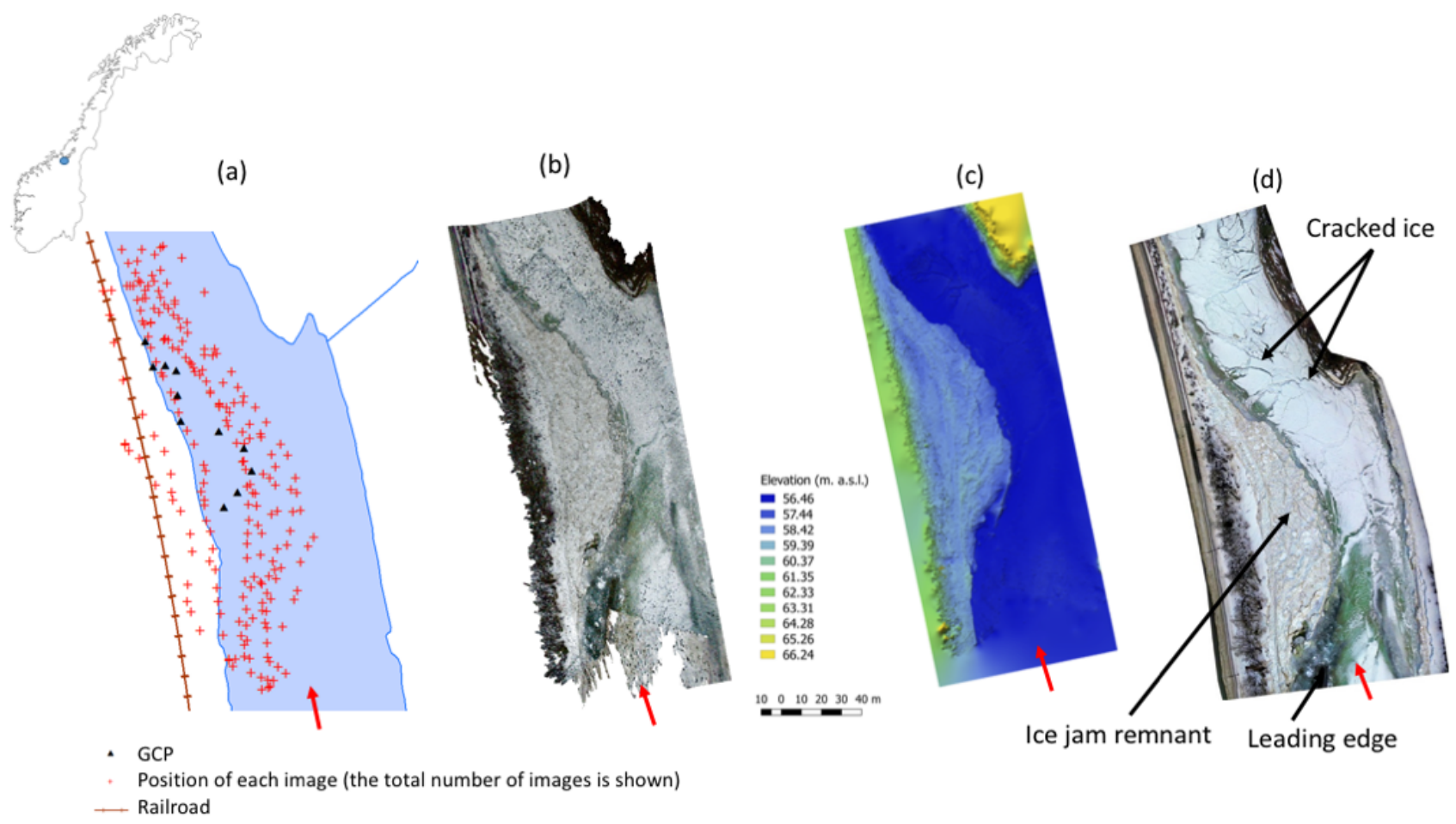

Figure 1. Stages of the process of mapping the Gaula site. Panel (a) shows the position of the drone for each image (crosses) and the ground control points (triangles) overlaid on a digital map of the river section. Panel (b) shows the dense point cloud for the same reach after processing the aerial imagery. Panel (c) shows the georeferenced digital surface model based on the point cloud. Panel (d) shows an orthophoto mosaic of the reach, showing both the ice jam to the left and an ice cover at different stages of formation. The red arrow shows the flow direction.

All GCPs and post-processing control points were measured during the drone flights. The GCPs and post- processing control points were surveyed using a Leica Viva RTK-GPS (spatial accuracy of $1-2 \mathrm{~cm}$ ), and they consisted of custom-made numbered markers $(25 \times 25 \mathrm{~cm})$ made of heavy red tarpaulin that were clearly visible on the drone images. GCPs were spread out over the measurement domains as much as conditions allowed, but only one bank was accessible to us at the Sokna site. At the Gaula site 11 GCPs were measured on the ice surface for georeferencing, and another 9 control points were measured to provide a simple control of accuracy of the surface model after processing. At the Sokna site, 9 GCPs were measured on the river bank since it was not possible to access the ice surface for safety reasons. The number of GCPs is based on previous experience of the necessary number of points to develop an accurate point cloud and surface model. The number of points is also in correspondence with Turner et al. (2012) who found similar results using 10 and 20 GCPs. The captured images and GCPs were processed using Agisoft Photoscan Pro version 1.3.0 (www.agisoft.com) into a georeferenced point cloud using the SfM workflow described by the following steps:

1. Photos were aligned and images with a quality index greater than 0.8 were included in the point cloud gen- eration. The quality index is computed by Agisoft Photoscan based on an evaluation of image sharpness, and experience shows that it is related to the spatial distribution of contrast in the images. The camera models were optimized and points with a RMS re-projection error of less than 0.2 were deleted from the cloud. Afterwards, the modelled camera positions and orientations were optimized again to improve the initial camera alignments, which were estimated by the software, based on common features between pairs of images.

2. GCPs and control points were imported to Photoscan and markers were manually identified and linked to the GCP. Each marker was identified on a minimum of three images before the georeferencing parameters were recalculated. In the Sokna case, the GCP showed an error that was considered too large, and this point was removed. The camera models were optimized once more and georeferenced clouds were generated.

3. The georeferenced point clouds were densified and the ground points were classified to create meshes. The meshes were then used to build surface models and generate orthophoto mosaics. 
Table 1. Root mean square error computed from GCP and control points. The error is reported for the combination of $x, y, z$ and error for each coordinate.

\begin{tabular}{lrrrrrrr}
\hline Measurement & $\begin{array}{r}\text { No. of } \\
\text { points }\end{array}$ & $\begin{array}{r}\text { Mean RMS } \\
\text { combined }(\mathrm{m})\end{array}$ & $\begin{array}{r}\text { Min RMSE } \\
\text { combined }(\mathrm{m})\end{array}$ & $\begin{array}{r}\text { Max RMS } \\
\text { combined }(\mathrm{m})\end{array}$ & $\begin{array}{r}\text { Long. } \\
(\mathrm{m})\end{array}$ & $\begin{array}{r}\text { Lat. } \\
(\mathrm{m})\end{array}$ & $\begin{array}{r}\text { Alt. } \\
(\mathrm{m})\end{array}$ \\
\hline Gaula GCP & 11 & 0.071 & 0.027 & 0.098 & 0.048 & 0.051 & 0.013 \\
Gaula control & 9 & 0.102 & 0.008 & 0.224 & 0.067 & 0.051 & 0.070 \\
Sokna GCP & 9 & 0.06 & 0.012 & 0.102 & 0.047 & 0.031 & 0.022 \\
\hline
\end{tabular}

Figure 1 shows the locations of the camera positions and the GCPs, the generated point cloud, the surface model and an orthophoto mosaic for the Gaula site. To extract crosssections and analyse the surface model generated in Photoscan, data were exported to ArcMap 10.5 (www.esri.com), and the tools in the 3-D analyst package were used to extract data from the surface model. The ground elevation under the ice jam in Gaula was taken from the $1 \mathrm{~m}$ Norwegian DEM provided by the Norwegian mapping agency (www.hoydedata.no).

\section{Results}

The quality of the georeferencing and post-processing control points was assessed using the root mean square error (RMSE) of the combined $x, y, z$ coordinates computed in Photoscan. Given the low amount of errors shown in Table 1 , the accuracy of the digital elevation model is considered good and ice features may be derived with high precision. A further comparison of the georeferenced images with features on the digital map of the area shows good correspondence between the features georeferenced in the images and the same features on the digital maps.

Figure 1d shows the orthophoto mosaic of the Gaula site, the extent of the ice jam, and the directional stacking of the ice floes accumulated in the jam. The formation of the ice cover on the river section outside the ice jam is also visible, and the pattern of a retrograde build-up of ice with the leading edge is clearly identifiable in the lower left edge of the picture. Furthermore, cracking and some shoving of the ice cover outside the ice jam can be seen, giving a clear indication of the mechanisms that form the ice cover on this reach of the river.

As shown in Fig. 2, cross-sections of ice jams were extracted from a combination of the SfM-derived surface model and ground elevation data from the $1 \mathrm{~m}$ resolution Norwegian national DEM. Based on visual observations after the ice event, and from observations in the field, the jam was assumed to be grounded for most of its area. At the Gaula site, the mean thickness of the ice layers were 1.82, 2.09 and $2.29 \mathrm{~m}$ for cross sections $\mathrm{A}-\mathrm{A}^{\prime}, \mathrm{B}-\mathrm{B}^{\prime}$ and $\mathrm{C}-\mathrm{C}^{\prime}$ respectively, and the sheer wall heights were $1.12,0.86$, and $1.60 \mathrm{~m}$ in cross sections $\mathrm{A}-\mathrm{A}^{\prime}, \mathrm{B}-\mathrm{B}^{\prime}$ and $\mathrm{C}-\mathrm{C}^{\prime}$, respectively. The mean thickness of the jam was $2.19 \mathrm{~m}$ and the maximum thick- ness was $3.56 \mathrm{~m}$. The ice jam volume was computed to be $6786 \mathrm{~m}^{3}$, covering a surface area of $3223 \mathrm{~m}^{2}$. This is most likely a minimum volume since it is probable that the Norwegian national DEM describes the river water surface rather than actual ground level, in particular for the last $10 \mathrm{~m}$ of each transect (Fig. 2).

Figure 3 shows a number of broken anchor ice dams at the Sokna site. Dam locations and computed elevations and sizes can be used to derive how the ice cover will develop in the reach. This forms the foundation for understanding the hydraulic impacts of ice in steep rivers, and results can be combined with measured hydraulic variables for further evaluation. As an example, Fig. 3 shows two vertical profiles of a broken anchor ice dam where the elevations of dam crests over the water surface is measured to 0.8 and $1 \mathrm{~m}$ respectively, indicating the elevated water level in the reach when the dams were complete.

\section{Discussion and conclusion}

An example of using a simple drone combined with SfM to map river ice is shown for two important types of ice, an ice jam and anchor ice dams. Using a relatively small number of GPS measured ground points, the point cloud was georeferenced and a surface model and an orthophoto mosaic were developed. Based on the georeferenced models, data on ice thickness, volume, and spatial distribution were extracted. Compared to previous measurements using GPS or total stations for mapping detailed spatial ice formations (e.g. Timalsina, 2014), the approach presented here removes the need to access the ice, which in the Sokna case would have been difficult or impossible due to the ice conditions. Even if access to the ice was possible, our new approach provides an amount and quality of data that cannot be matched by difficult and time-consuming collection of manual measurements.

A challenge with remote sensing is to assess ice thickness over flowing water, and this is also the case using the drone and SfM method. At the Gaula ice jam, it was relatively simple to compute ice volumes and derive ice cross sections for ice grounded on a surface with known ice-free geometry, but in cases where river ice has open water sections the problem is more complicated. This is illustrated by considering the conditions shown in the Sokna case (Fig. 3). Anchor ice 

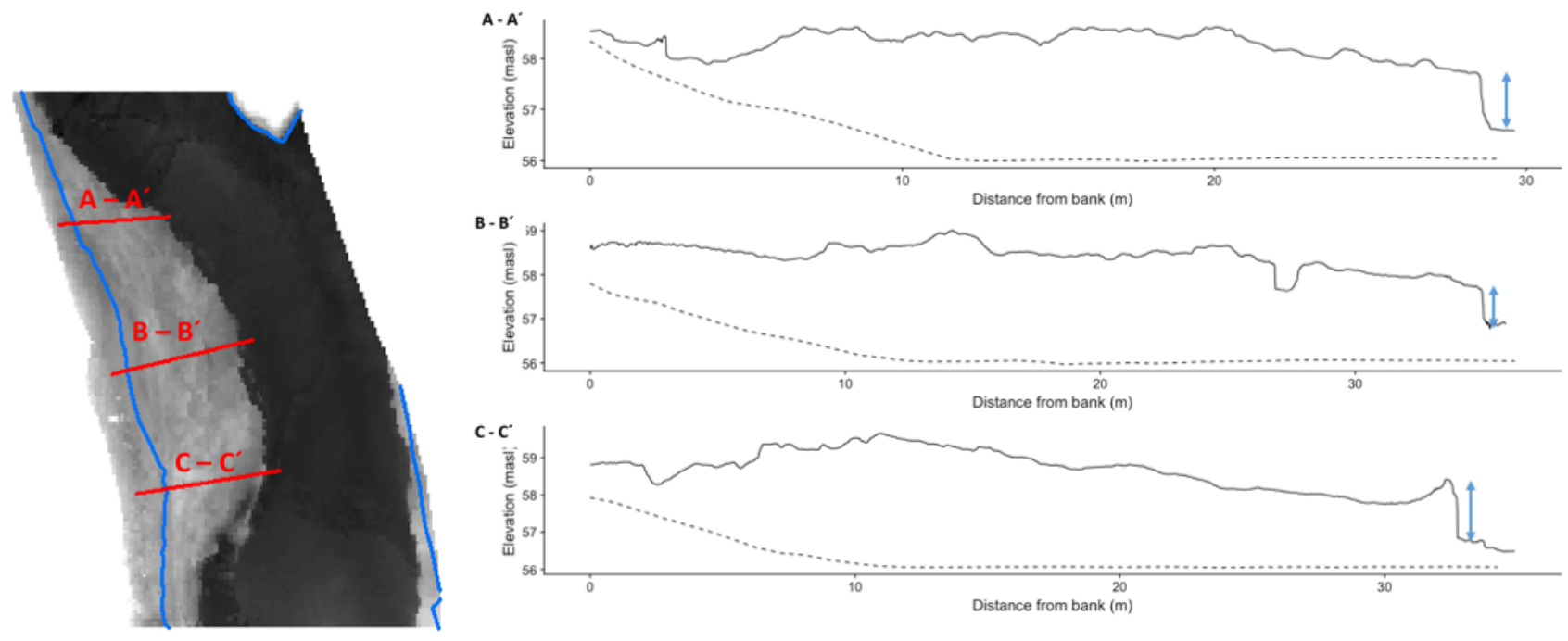

Figure 2. Cross sections through the Gaula ice jam at three different locations marked $\mathrm{A}-\mathrm{A}^{\prime}, \mathrm{B}-\mathrm{B}^{\prime}$ and $\mathrm{C}-\mathrm{C}^{\prime}$. The height of the shear wall of the ice jam is marked with an arrow in each cross section. The dashed line indicates the ground level from the $1 \mathrm{~m}$ resolution Norwegian DEM.
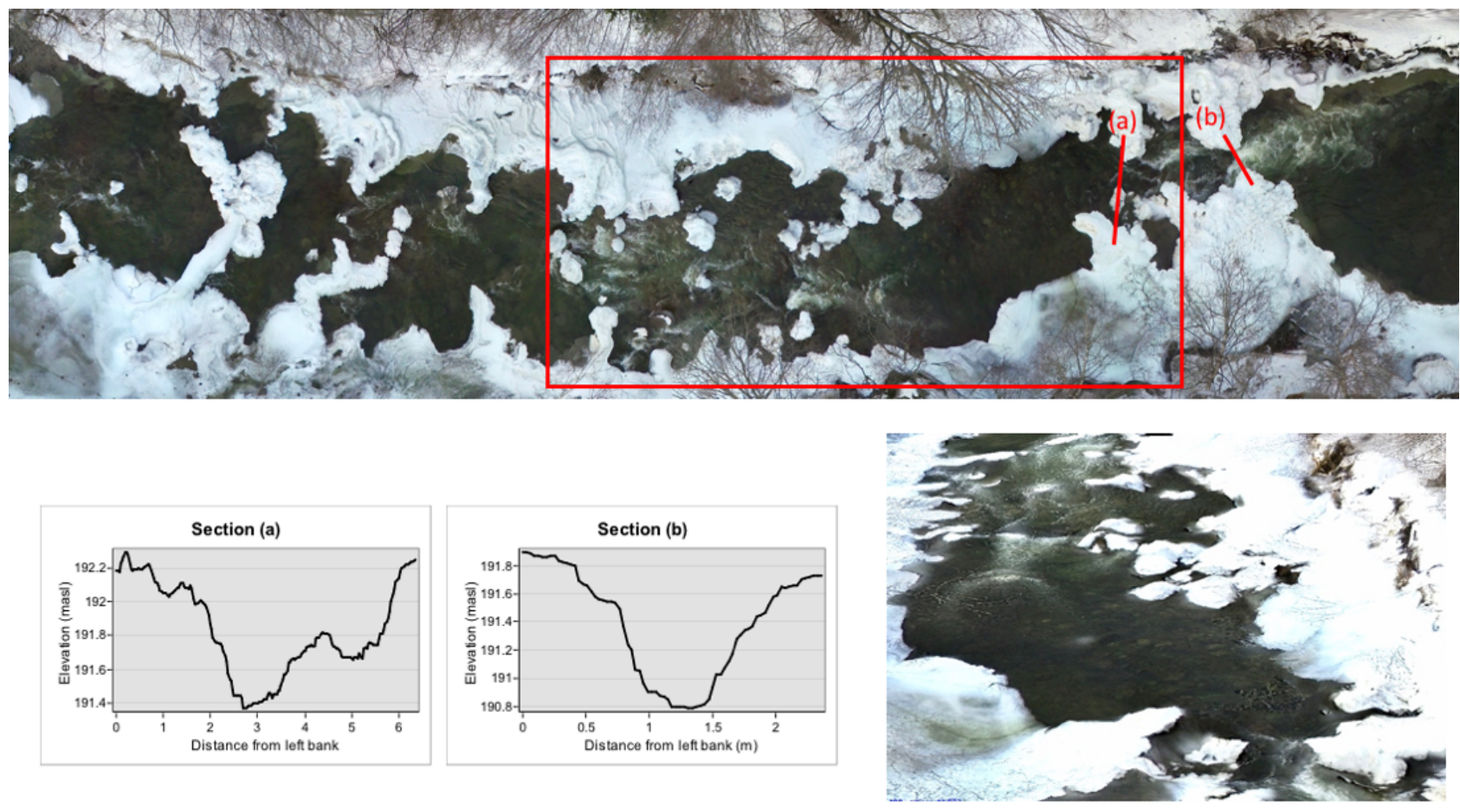

Figure 3. Partly broken anchor ice dams in the Sokna reach. The upper picture shows an orthophoto mosaic of the reach, the lower graphs shows the two sections (a) and (b) marked on the picture and the picture shows the area in the red rectangle as seen from downstream.

dam positions and their width and height can be derived from the orthophoto mosaic and the surface model, but unlike the Gaula case, no ice-free geometry of the river was available to assess the volume of ice. A possible approach is to derive the elevation of the level of the open water from the SfM gener- ated surface model and then use this to assess the thickness of the anchor ice dams seen in the mosaic. At the Sokna site, we could see that the open water would give a reasonable assessment of the thickness of the dams, but this approach requires field observations to confirm the method. In general, 
using the visible water surface has its limitations due to the turbulent surface of the water, and because the rocks and outcroppings known to be important for anchor ice dam formation may not be visible in the images captured after the ice is formed. To facilitate this approach, a flight during ice-free conditions or some other kind of measurement campaign is needed to capture the size and position of large boulders and other morphological conditions that control placement of anchor ice dams. Together with the dam positioning methodology described herein, this approach could be used to accurately determine the favourable conditions for development of anchor ice dams and the size of the dams. The formation of anchor ice in Sokna and other similar small rivers is crucial for the formation of an ice cover and for the in-stream flow conditions (Timalsina, 2014). Therefore, understanding the mechanisms for formation and location of the ice would make analysis of winter conditions more precise and would improve the ability to predict dam positions.

Our experience suggests that the ice cover was better detected and represented under snow free conditions than from a comparable surface with an undisturbed snow cover. It is therefore advisable to fly the reach as soon as possible after an ice event has occurred and preferably before snow cover develops. In general, the DJI Phantom 3 Professional is limited in poor lighting conditions due to the small $6.17 \times 55 \mathrm{~mm}$ sensor. Compared to bigger sensors, the influence of lighting conditions can be drastic as shutter speed is decreased, with a commensurate increase of the aperture. Because of this, the camera system is more sensitive to the influence of vibrations and movement of the UAV caused by wind. Further, bright light with dark shadows can result in poor picture quality as the camera sensor can be overloaded by bright reflections from unshaded areas, whereas shaded areas may lack suitable information for SfM applications. Therefore, we recommend manual camera settings on the Phantom 3 Professional to ensure sufficient image quality for post processing. Automatic waypoint navigation (e.g. in this case with the DJI GS Pro application) can help to create a dataset with good coverage of the site and sufficient image overlapping. However, all autonomous navigation and auto camera settings increase the risk of poor picture quality, especially under less than optimal lighting conditions. Regardless of the approach used, data quality must be checked in the field to prevent data gaps caused by poor image acquisition. New versions of drones are appearing regularly, and improved sensor technology and light handling will improve picture quality, feature matching between cameras, and depth maps. This will increase the accuracy of the SfM generated surface model and orthophoto mosaics.

Labelled regions were manually extracted for corresponding physical features (e.g. "cracks", "anchor ice") following generation of the orthophoto mosaic. However, processing algorithms for advanced pixel and object-based image classification have been used by the remote sensing community for decades, and geoscience practitioners have already be- gun to develop new methods specifically tailored to 3-D point clouds derived from SfM models (Stickler et al., 2010). Once workflows for the identification and classification of physical features specific to ice processes and types have been established, such as presented herein, it can reasonably be expected that machine learning may be applied to more efficiently classify large quantities of orthophoto imagery.

Compared to other methods, using a drone and SfM for river ice assessment is an efficient method particularly suitable for small and medium sized rivers. Using satellites is difficult in smaller watersheds due to the small size of the rivers compared to satellite pixels, and the data can be costly. Using SfM with other aerial platforms like planes or helicopters is more expensive to operate, and are also not as versatile as a drone in narrow valleys and at sites with heavy bankside vegetation. Manual measurements take far more time if similar detail is needed (and may not be possible in practice), and can be difficult due to necessary safety restrictions related to work on ice covered rivers. Though no photographic images are produced, the use of a terrestrial laser scanner is a possible bankside remote sensing alternative (Brostow et al., 2008) For larger or longer reaches, the number of scan positions occupied may lead to a more extensive field campaign, and further processing and integration of point clouds from many positions may also consume time and effort.

There are limitations to the application of the DJI Phantom 3 Professional used here. From experience, we expect practical flight range of about $1000-1300 \mathrm{~m}$ in open terrain when flying in non-autonomous mode. This limits the application in large rivers, and makes it necessary to fly from several locations to cover longer reaches. The application of the small drone is also influenced by wind, and calm days are recommended both due to operation and for the best possible image quality. Another issue relates to battery life in cold weather. The flight time is around $20 \mathrm{~min}$, and it is necessary to pay attention to the battery status to avoid sudden loss of voltage in cold batteries. For sustained operation in cold climates several batteries are recommended, and spare batteries should be kept as warm as possible. A final issue to consider is operational constraints set by applicable aviation regulations that must be consulted before each flight, which may limit system size, mass, range, elevation, timing, etc.

The approach presented here is applicable to several issues in river ice research, modelling and management. As seen in Fig. 1d, the mechanisms of ice formation can be derived from the pictures, and since the method is not very time consuming, repeating measurements over a short time is viable and could provide detailed data on the freeze-up process. When combined with measurements of climate and hydraulic variables, the surface model and orthophoto mosaic from the SfM processed drone imagery could benefit process understanding and model development. Data can also be used in the calibration and validation of ice models. Mapping of ice jams could provide a basis for the assessment of ice volumes and the configuration of floes and ice elements that make up 
the jam. These data are critical for understanding the river ice breakup processes and may aid in assessing potential damages that can result.

Data availability. The images used in the analysis can be downloaded from: Sokna: http://folk.ntnu.no/knutal/TC/Sokna.zip; Grana: http://folk.ntnu.no/knutal/TC/RAW.zip. The file-size is about 5 GB each.

Author contributions. All authors contributed to the design of the field work based on previous measurements by KA. All authors participated in the field work, and $\mathrm{CH}$ flew the drone and acquired the images. KA did the analysis supported by JAT and $\mathrm{CH}$, and PZ provided the ice-free geometry data. KA wrote the manuscript with input from all co-authors.

Competing interests. The authors declare that they have no conflict of interest.

Acknowledgements. JAT and $\mathrm{CH}$ participated in the field work as part of the workshop on data processing from images gained by unmanned aircraft systems that was funded by the European Economic Area (EEA) Grant "Restoration of the aquatic and terrestrial ecosystems at Fundu Mare Island" (Project Number RO02-0008) with financial contributions from Norway and Romania. The authors wish to thank the three reviewers who provided very useful input to the manuscript.

Edited by: Peter Morse

Reviewed by: Karl-Erich Lindenschmidt, Shawn Clark, and Mark Loewen

\section{References}

Ansari, S., Rennie, C., Seidou, O., Malenchak, J., and Zare, S.: Automated monitoring of river ice processes using shore-based imagery, Cold Reg. Sci. Technol., 142, 1-16, https://doi.org/10.1016/j.coldregions.2017.06.011, 2017.

Arif, M., Gülch, E., Tuhtan, J., Thumser, P., and Haas, C.: An investigation of image processing techniques for substrate classification based on dominant grain size using RGB images from UAV, Int. J. Remote Sens., 38, 2639-2661, https://doi.org/10.1080/01431161.2016.1249309, 2016.

Beltaos, S.: River ice jams, Water Resources Publishers LLC, Highlands Ranch, Colorado, 372 pp., 1995.

Beltaos, S. and Kääb, A.: Estimating river discharge during ice breakup from near-simultaneous satellite imagery, Cold Reg. Sci. Technol., 98, 35-46, 2014.

Brooks, R. N., Prowse, T., and O'Connel, I. J.: Quantifying Northern Hemisphere freshwater ice, Geophys. Res. Lett., 40, 11281131, https://doi.org/10.1002/grl.50238, 2013.

Brostow, G., Shotton, J., Fauqueur, J., and Cipolla, R.: Segmentation and recognition using structure from motion point clouds,
European Conference on Computer Vision, Springer, Berlin, Heidelberg, 44-57, 2008.

Chu, T. and Lindenschmidt, K.-E.: Integration of space-borne and air-borne data in monitoring river ice processes in the Slave River, Canada, Remote Sens. Environ., 181, 65-81, https://doi.org/10.1016/j.rse.2016.03.041, 2016.

Mermoz, S., Allain-Bailhache, Bernier, M., Pottier, E., Van Der Sanden, J., and Chokmani, K.: Retrieval of River Ice Thickness From C-Band PolSAR Data, IEEE T. Geosci. Remote, 52, 30523062, https://doi.org/10.1109/TGRS.2013.2269014, 2014.

Nolan, M., Larsen, C., and Sturm, M.: Mapping snow depth from manned aircraft on landscape scales at centimeter resolution using structure-from-motion photogrammetry, The Cryosphere, 9, 1445-1463, https://doi.org/10.5194/tc-9-1445-2015, 2015.

Prowse, T. and Culp, J.: Ice breakup: a neglected factor in river ecology, Can. J. Civil Eng., 30, 128-144, 2003.

Ryan, J. C., Hubbard, A. L., Box, J. E., Todd, J., Christoffersen, P., Carr, J. R., Holt, T. O., and Snooke, N.: UAV photogrammetry and structure from motion to assess calving dynamics at Store Glacier, a large outlet draining the Greenland ice sheet, The Cryosphere, 9, 1-11, https://doi.org/10.5194/tc-9-1-2015, 2015.

Smith, M. and Vericat, D.: From experimental plots to experimental landscapes: topography, erosion and deposition in subhumid badlands from Structure-from-Motion photogrammetry, Earth Surf. Proc. Land., 40, 1656-1671, 10.1002/esp.3747, 2015.

Smith, M., Carrivick, J., and Quincey, D.: Structure from motion photogrammetry in physical geography, Prog. Phys. Geogr., 40, 247-275, https://doi.org/10.1177/0309133315615805, 2016.

Stickler, M., Alfredsen, K., Linnansaari, T., and Fjeldstad, H.-P.: The influence of dynamic ice formation on hydraulic heterogeneity in steep streams, River Res. Appl., 26, 1187-1197, 2010.

Timalsina, N. P.: Ice conditions in Norwegian rivers regulated for hydropower: An assessment in the current and future climate, $\mathrm{PhD}$ thesis, Department of Hydraulic and Environmental Engineering, Norwegian University of Science and Technology, Trondheim, 2014.

Turcotte, B. and Morse, B.: Ice processes in a steep river basin, Cold Reg. Sci. Technol., 67, 146-156, 2011.

Turner, D., Lucier, A., and Watson, C.: An Automated Technique for Generating Georectified Mosaics from Ultra-High Resolution Unmanned Aerial Vehicle (UAV) Imagery, Based on Structure from Motion (SfM) Point Clouds, Remote Sens., 4, 1392-1410, https://doi.org/10.3390/rs4051392, 2012.

Vasquez-Tarrio, D., Borgniet, L., Liebault, F., and Recking, A.: Using UAS optical imagery and SfM photogrammetry to characterize the surface grain size of gravel bars in a braided river (Veìneìon River, French Alps), Geomorphology, 285, 94-105, https://doi.org/10.1016/j.geomorph.2017.01.039, 2017.

Westoby, M., Brasington, J., Glasser, N., Hambrey, M., and Reynolds, J.: "Structure-from-Motion" photogrammetry: A lowcost, effective tool for geoscience applications, Geomorphology, 179, 300-314, https://doi.org/10.1016/j.geomorph.2012.08.021, 2012.

Woodget, A., Austrums, R., Maddock, I., and Habit, E.: Drones and digital photogrammetry: from classifications to continuums for monitoring river habitat and hydromorphology, WIRES Water, 4, e1222, https://doi.org/10.1002/wat2.1222, 2017. 